\title{
Previdência Social: a saga entre trabalho e adoecimento
}

\author{
Evânia Maria Oliveira Severiano \\ Universidade Federal do Ceará (UFC)
}

\author{
Alano do Carmo Macêdo \\ Universidade Federal de Santa Catarina (UFSC)
}

\section{Previdência Social: a saga entre trabalho e adoecimento}

Resumo: Este artigo propõe reflexões acerca do acesso dos sujeitos ao reconhecimento do direito previdenciário. A abordagem qualitativa possibilitou a análise do movimento das realidades dos usuários. Foram realizadas entrevistas individuais e grupos focais com usuários da política pública previdenciária na Gerência Executiva do Instituto Nacional do Seguro Social em Fortaleza, Ceará. Problematiza, ainda, um espaço público tocado pela linguagem do direito, ensejando possibilidades do saber e poder popular.

Palavras-chave: Previdência Social. Reconhecimento de direito. Trabalho. Benefício por incapacidade.

\section{Social Security: the saga between work and illness}

Abstract: This article proposes reflections about access by individuals to recognition of the right to social security. The qualitative approach allowed an analysis of shifts in the realities of users. Individual and group interviews were conducted with users of the public social security system at the Executive Administration of the National Social Security Institute in Fortaleza, Ceará. The article also problematizes a public space touched by the language of the law, creating possibilities for popular knowledge and power.

Keywords: Social Security. Recognition of rights. Work. Disability Benefits. 


\section{Introdução}

A previdência social aproxima-se de seu centenário com histórico de um direito social frequentemente submetido a contrarreformas, outrossim, impulsionadas pelas lutas sociais e pela complexa e criativa tensão entre regulação e emancipação. $\mathrm{O}$ ingresso profissional dos autores ocorrera em momentos distintos, mas correlatos, no Instituto Nacional do Seguro Social (INSS). Um destes, em 1997, tempos que o Brasil materializava as primeiras orientações neoliberais nos governos dos "Fernandos": Collor de Mello e Henrique Cardoso. Nesse contexto, o serviço público consubstanciava várias contradições, dentre as quais: a expansão do processo de terceirização, redução dos gastos públicos e privatizações como expressões da Reforma do Estado $^{1}$. O outro autor ingressou em 2009 no INSS, quando o cenário político no governo Lula, já no segundo mandato, revelava um país menos pobre, mas ainda desigual, em tempos de armadilhas econômicas e ideopolíticas orquestradas com maestria pela burguesia rentista sob o aval do Estado.

No processo de trabalho cotidiano, enquanto assistentes sociais, presenciamos situações que explicitam um amplo e heterogêneo movimento de sujeitos que percorrem longos e tortuosos caminhos em busca do direito previdenciário. Geralmente, são vítimas da exponenciação das expressões da questão social e seus espraiamentos no mundo do trabalho no contexto de mundialização do capital, nos termos de Chesnais (1996). Para qualificar o debate é pertinente compreendermos os elementos contemporâneos da nova conformação produtiva que vêm se desenvolvendo no país, quais sejam: terceirização, subcontratação, crescente informalidade, entre outros, sob a lógica da sociabilidade capitalista. Tais aspectos afetam as dimensões objetivas e subjetivas da classe trabalhadora, bem como repercutem substancialmente nas formas de resistência dos movimentos sociais e na institucionalidade do Estado social de direitos (ANTUNES, 2001, 2006; ALVES, 2007).

Nossas inquietações emergem de situações recorrentes dos sujeitos que buscam o benefício por incapacidade e durante o período de espera do reconhecimento desse direito, sem remuneração, submetem-se a trabalhar em outras atividades a fim de sobreviver. Muitos desses sujeitos que demandam a previdência social enfrentam barreiras e criam mecanismos para superá-las e afirmar os direitos sociais nessa área, objetivando o reconhecimento de suas demandas pela esfera estatal. Assim, elaboramos as seguintes indagações: quais os significados dessa saga vivenciada por essas pessoas? Quais as repercussões nas suas condições objetivas e subjetivas? Como ocorre a materialidade ou não dessa política de direitos a partir do seu processo instituído e instituinte?

Nesse sentido, constituímos como proposta investigativa, por ocasião da tese de doutoramento ${ }^{2}$, compreender a política previdenciária pública brasileira no contexto da seguridade social em tempos de desigualdades e paradoxos, centrando nos sujeitos que demandam benefício por incapacidade e vivem o dilema do trabalho, ou de sua ausência, e a transversalidade do processo saúde-doença, geralmente ocasionado pela ocupação profissional. Com isso, nos aproximamos dessa importante política com a proposta de evidenciar as relações entre o que é instituído pelo sistema de proteção social e os sujeitos de direitos que pleiteiam tal acesso.

\section{Percurso metodológico}

A escolha da abordagem qualitativa possibilitou compreender a construção da diferentes realidades de determinados coletivos a partir de suas experiências na busca pelo acesso ao direito previdenciário. A perspectiva crítico-dialética direcionou a investigação dada a necessidade de desvendar o caráter de totalidade do fenômeno analisado, seu aspecto contraditório e dinâmico, indo, assim, à essência da realidade social. Conhecer o ser social exige um esforço de sínteses que possibilitam, ao final, conhecer a totalidade social da sociedade burguesa em sua complexidade, amparada na economia política.

A investigação compreendeu três momentos correlatos e distintos à dinâmica espaço-temporal, pautada pela necessidade do conhecimento da realidade dos interlocutores à luz da teoria social crítica, com vistas a contribuir para a transformação desse contexto. Primeiramente, foi realizada revisão bibliográfica, consulta a documentos oficiais e visitas aos locais da pesquisa numa tentativa de aproximação ao objeto pesquisado. Em seguida foram definidos os tipos de técnicas de obtenção de dados, com a realização de entrevistas e grupos focais com os usuários da previdência social. Antes da entrevista foi aplicado um pré-teste no qual identificamos o tempo de execução, a necessidade de reformulações, acréscimos e retirada de algumas questões. Com relação aos grupos focais importa destacar que, embora houvesse o estabelecimento de critérios prévios, a organização não se resume aos mecanismos objetivos, mas diversos fatores foram levados em consideração, ponderados pela dinâmica das múltiplas relações sociais estabelecidas nesse contexto.

O universo da pesquisa contemplou um total de dez grupos focais, tendo como média de participação entre sete e dez sujeitos, resultando na escuta de 82 interlocutores. Ao final de cada encontro, após a transcrição das gravações, leitura e releitura, observamos a repetição de dados, indicando-nos a saturação teórica, ou seja, os 
conteúdos já não traziam novidades (FLICK, 2009). A investigação foi realizada na Gerência Executiva do INSS em Fortaleza (Gexfor), no estado do Ceará. Os critérios para escolha dos sujeitos foram: segurado com indeferimento do pedido de benefício por incapacidade; e impetrar recurso na esfera administrativa ou judicial.

Por fim, ocorreu a descrição, o tratamento e a análise dos dados coletados na pesquisa. Durante a análise, as questões foram agrupadas em tópicos específicos e interpretadas considerando as falas comuns e divergentes apresentadas pelos interlocutores, ou seja, após foram comparação e confrontação, foram extraídos significados das falas e dos registros, além de realçar os constantes ditos e os nãos ditos ${ }^{3}$.

\section{A saga dos sujeitos no reconhecimento ao direito previdenciário}

Inicialmente, o que nos instigou a pesquisar o problema em tela fora a situação de uma usuária que tinha chegado a óbito durante o processo de luta pelo direito ao Benefício de Prestação Continuada da Lei Orgânica da Assistência Social (BPC/Loas). Ouvimos depoimentos de seus familiares e vizinhos que lamentavam e diziam que o direito chegou tarde demais, pois, em vida, muito havia lutado para receber esse direito o qual não chegou a tempo de usufruí-lo. Durante a trajetória e espera sem remuneração, sobrevivia da solidariedade dos vizinhos e familiares que apoiavam financeiramente. Ainda que este seja um benefício da política de assistência social, sua operacionalidade ocorre no âmbito do INSS. Assim, os dilemas, nos (des)caminhos destes que o pleiteiam, não são muito diferentes daqueles que buscam o acesso ao benefício por incapacidade na política previdenciária. Nesta trajetória, observamos que algumas representações coletivas de categorias profissionais ${ }^{4}$ questionavam o marco legal da previdência social e de sua estrutura administrativa, por considerarem não condizente com as novas dinâmicas de ocupação e renda do heterogêneo mundo do trabalho em tempos de crise estrutural do capital (MÉSZÁROS, 2009; ANTUNES, 2001).

Por outro lado, assistimos aos diagnósticos governamentais que apontam déficits da previdência devido aos desafiantes fenômenos, tais como a expectativa de vida com o aumento da longevidade, dificuldades na prestação de um atendimento eficiente, justo, descentralizado e ágil para a diversidade de usuários, além do desafio de universalidade do direito previdenciário, sobretudo, aos trabalhadores urbanos informais. Algumas abordagens governamentais situam na berlinda as conquistas obtidas no campo dessa política pública. Em contraposição, as entidades sociais e sindicais vêm se apropriando de outros estudos, fora da lógica do Governo, com dados que contrariam algumas afirmações governamentais, sobretudo, acerca do financiamento superavitário da política previdenciária, analisando-se no contexto da seguridade social, conforme orientação constitucional.

Nos registros realizados em trabalho de campo foi

\section{Geralmente os trabalhadores}

se sentem ameaçados de

\section{perder o emprego, buscam o}

INSS e são jogados à própria

sorte. simbólica a expressão utilizada por um trabalhador bancário na primeira reunião da qual participamos como observadores do Grupo de Apoio a Saúde dos Bancários $(\mathrm{Gasb})^{5}$ que, ao se retirar do encontro, falou: "vou iniciar minha via crucis". Referindo-se ao inicio do processo de pedido de afastamento do trabalho por adoecimento. Havia relatado, durante a reunião, que estava, novamente, sentindo intensas dores musculares ocasionadas pela Lesão por Esforço Repetitivo (Ler). Como se trata de uma doença geralmente ocasionada pelo trabalho, há necessidade de emissão ou reabertura de Comunicação de Acidente do Trabalho (CAT). O interlocutor revela que a via crucis já começa aí, pois, quase sempre o empregador, nesse momento, põe dificuldade ou expressa sentimento de rejeição; depois, vem a trajetória percorrida no INSS para reconhecer o direito, que pode ser um caminho permeado por humilhações. Ressaltamos que tal sentimento fora verbalizado pelos sujeitos da pesquisa de forma recorrente no processo de investigação. De imediato, é necessário estabelecer três relações complexas: com o empregador; com o atendimento na política de saúde, para esclarecer o diagnóstico; e com o INSS, para reconhecer o direito que obrigatoriamente passará por uma avaliação médico-pericial, responsável por definir a existência ou não da incapacidade para o desempenho das atividades laborativas habituais de modo temporário ou permanente.

A expressão via crucis, em latim, significa o caminho da cruz que, segundo a tradição cristã, simboliza o caminho que Jesus percorreu do julgamento até a crucificação e morte. Também é chamado de caminho doloroso, que representa cada uma das passagens do martírio de Cristo ${ }^{6}$. É possível fazer analogia entre a expressão via crucis e as cenas narradas pelos sujeitos nas trajetórias que enfrentam para galgar o reconhecimento do direito previdenciário. Alguns desses usuários, ou já perderam os vínculos com o mercado de trabalho assalariado e protegido, ou estão ameaçados por estas situações. Uma vez adoecidos, considerados 
improdutivos, às vezes, com idade avançada, situações que geralmente foram motivadas pelo tipo de trabalho que realizavam. Chegam fragilizados aos balcões dos serviços públicos, pois, ao perderem os vínculos, geralmente vão-se os projetos, as motivações no processo de viver e a saúde. Buscam, na maioria das vezes, apenas hospitalidade ${ }^{7}$ para se nutrirem de dignidade, autoestima, mas nem sempre encontram. Na previdência social parece que as leis, normas e decretos imperam com força soberana, ditando aqueles a quem é possível ceder lugar. Não se oferece hospitalidade ao que chega anônimo ou a qualquer um que não tenha o estatuto social vinculado, direta ou indiretamente, a sua forma de inserção no mercado de trabalho. Nesse processo de conquista da cidadania e dos direitos não se retrata apenas a estrutura formal de uma sociedade, pois também se evidencia a ação dos sujeitos, de suas lutas e de seu reconhecimento na arena pública. Assim, os direitos podem ter a expressão de princípios reguladores das práticas sociais, são concebidos como expressões de uma ordem estatal e como uma gramática civil (TELLES, 1999; CANCLINI, 2008).

A previdência pública, sendo uma elaboração social que envolve o protagonismo dos trabalhadores e o esforço de se prover condições de reprodução da força de trabalho, volta-se a substituir a renda auferida pelo trabalho por um direito monetário previdenciário no momento de incapacidade produtiva para desenvolver as atividades laborativas, de modo temporário ou permanente, que pode ocorrer motivado pela idade avançada, doença, invalidez ou morte. Desse modo, importa considerar tal contexto, pois a produção dos dados registrados nos diversos momentos de apreensão das informações foi permeada de emoções e sentimentos de incerteza, de reconhecimento e também de indignação ou mesmo de conformismo, bem como de outras manifestações expressas nas narrativas dos sujeitos. Ouvimos relatos que trazem não somente os sentimentos e expectativas individuais, mas também evocação coletiva sobre suas necessidades:

Sempre quis desabafar [...]. Ai, eu lhe encontrei (PELEJA).

Nós estamos aqui com vocês, é uma maravilha, nós vamos sair maneiras daqui num é não? (INCERTEZALHUMILHAÇÃO).

Tem tão poucas pessoas que nos escutam que quando agente acha, aproveitamos para desabafar né? A gente vê a vida do outro e o outro vai já acrescentando outras coisas e a gente vai aprendendo (ACESSOLAMIZADE).

Essas verbalizações representam a complexidade das múltiplas relações sociais que compõem a sociabilidade desses sujeitos nos seus contextos de vida, de trabalho e de adoecimento, conformações da realidade da classe trabalhadora no momento do capitalismo contemporâneo. Expressões de incerteza e instabilidade, de desemprego, de formas precárias de ocupação e (des)proteção social trazem preocupações e motivam ou agravam o adoecimento daqueles que dependem da venda de sua força de trabalho para sobreviver. Precarização com degradação das condições de trabalho são, portanto, as portas de entrada para esse modo de ser e de viver nesse momento contemporâneo da mundialização do capital (CHESNAIS, 1996; ANTUNES, 2001, 2006; ALVES, 2007). Tais condições podem ser evidenciadas na reprodução da narrativa a seguir:

Estou com dois contratos seguidos trabalhando em uma empresa na plataforma desde 1989 pra cá. A gente faz contrato de empresa em empresa. Meu contrato agora vai até o ano de 2016. Sou ajudante de metalurgia, sempre trabalhei nessa área. Mas achava que não tinha nenhum problema de saúde. De seis em seis meses fazemos exames de rotina exigidos pela empresa. No decorrer desses exames, agora, acharam uma mancha no meu pulmão. Estou preocupado. O trabalho lá é doze horas de serviço [...], trabalho com muita poeira, muito pó de lixadeira e com muitos produtos químicos. Mesmo com máscara, inalamos muito gás, é o maior risco que tem. [...] O doutor pediu todos os exames pra eu fazer e fiz. [...] Tenho plano de saúde [...]. O Médico perito pediu os últimos exames que fiz na empresa. [...] O Técnico de segurança do trabalho me acompanhou. [...] O doutor falou para ele: 'rapaz, ele trabalhou o ano todinho de 2010, doente, do mês de outubro de 2010 até agora. O rapaz está com o pulmão manchado e vocês não sabiam disso?'. Ele disse: 'Não, eu não sabia doutor, porque a gente não tem o direito de entrar no processo, de ver o laudo de cada funcionário. Quando o médico viu o raio-x ele disse: 'você está com um ano que trabalha doente'. [...] Aí eu fico andando de mão em mão sem saber a quem eu vou recorrer desse período que eu estava doente, não sei ainda o que fazer, pois eu nem sabia que eu já estava doente. O doutor da empresa ficou abismado porque eu disse: doutor eu vou culpar quem? É a primeira vez que vim para a perícia médica para pedir o auxílio doença. [...] A doença foi adquirida no trabalho, eles devem ver isso [...] Também a minha preocupação é esse ano que trabalhei doente. [...] É ruim, a pessoa inocentemente está trabalhando normal como eu trabalho. Eu nunca botei um atestado por uma dor de cabeça. Esses anos todos foi trabalhando pesado (INDIGNAÇÃO, grifos nossos). 
O relato expressa surpresa e indignação ao se deparar com a notícia de que já portava sinais de adoecimento há mais de um ano, evidenciado em exames periódicos. Sem conhecimento dessa situação, continuou trabalhando nas mesmas condições que podem ter ocasionado o problema de saúde pulmonar. Demonstrou interesse em buscar apoio para recorrer desse período em que trabalhou doente, momento oportuno que orientamos a procurar o Centro de Referência em Saúde do trabalhador (Cerest) e o sindicato.

Em artigo da revista Caros Amigos, Zinet (2012) revela resultados de uma pesquisa do Departamento Intersindical de Estatística e Estudos Socioeconômicos (Dieese) que mostra a crescente precarização das condições de trabalho e aponta que mais de 25,5\% (10 milhões) de trabalhadores formais já estão com emprego precário, imersos na terceirização. Em síntese: a terceirização ou subcontratação é uma das estratégias para recuperação da taxa de lucro. Os terceirizados recebem salário $27,1 \%$ menor do que os contratados diretamente, com acréscimo no tempo da jornada de trabalho de 43 horas, em média, e com severas dificuldades para garantir direitos trabalhistas e previdenciários. Os sindicatos se deparam com barreiras no processo de mobilização e de organização das lutas desses trabalhadores. Segundo ainda Zinet (2012), oito em cada dez acidentes acontecem com terceirizados. Nos casos que resultam em morte, quatro entre cinco ocorrem em empresas prestadoras de serviços. Infelizmente, as condições de trabalho dos terceirizados, ou são desconhecidas ou são relegadas a segundo plano e as empresas que terceirizam pouco se responsabilizam pelos atos dos seus fornecedores.

Nas falas abaixo, os sujeitos demonstraram estes sentimentos pela maneira como foram, resolutivamente, encaminhadas suas situações. Outro informante, o Culpaljustiça, manifestou-se sobre o acidente ocorrido ao mesmo tempo em que apresentou desejo de justiça pelo não reconhecimento do pedido de aposentadoria especial, pois, segundo ele, já deveria estar aposentado:

Trabalho em uma empresa do ramo têxtil, completo dois anos no próximo mês. De seis a sete meses pra cá, eu venho sentindo muitas dores no calcanhar [...]. Trabalho praticamente o horário todo com botas acochadas e duras. Procurei o médico da firma e fui encaminhado para exames [...] ele constatou que eu tenho tendiopatia - o famoso esporão de galo [...]. Ele me deu 30 dias e me encaminhou para o INSS [...]. Além de não poder trabalhar de sapato, tem que ser o calçado que a firma dá. Aí o técnico de segurança do trabalho solicitou à empresa outros calçados, pediu um laudo para o médico e a empresa comprou os sapatos (RECONHECIMENTO, grifos nossos).

Eu trabalho em uma empresa que fabrica sal mineral no município X. Eu tive um problema interno, e aío médico pediu pra eu fazer uma cirurgia de reparação. Fiz a cirurgia, está com dez dias, tive que dar entrada porque ele me deu um atestado de 30 dias, pra receber o restante do mês. Mas, tudo normal [...]. Tudo certinho. Primeira vez que estou aqui (CONFORMAÇão, grifos nossos).

Perdi parte do dedo na máquina de 'filatório', tenho 31 anos de empresa, na mesma função na empresa têxtil. Descuido só. [...] Porque, com tanta experiência, 31 anos [...]. Eu ia voltar, aí o médico deu mais 30 dias. Eu já devia estar aposentado. Entrei em 2008 com o pedido de aposentadoria especial, estou com advogado, até hoje. Está na justiça (CULPA\JUSTIÇA, grifos nossos).

As queixas de adoecimentos são atribuídas às atividades, condições de trabalho com jornadas extenuantes, aos modos diferentes de acompanhamento e encaminhamentos aos problemas de saúde apresentados pelos trabalhadores. Tudo isso depende da empresa, das relações e condições de trabalho, se são empregados de carteira assinada, subcontratados, terceirizados de grandes corporações ou trabalhadores informais. Cada especificidade de situação trabalhista ocasionará, ao trabalhador adoecido, modos distintos de proteção e acompanhamento. Por isso foi comum ouvir relatos de alguns que tinham ao seu dispor planos de saúde privados e equipe de segurança do trabalho acompanhando com iniciativas de proteção a saúde. Os interlocutores revelaram que essa não é, porém, uma garantia para todos. Há empresas que nem apoiam e nem acompanham as situações de adoecimentos dos empregados. Geralmente os trabalhadores se sentem ameaçados de perder o emprego, buscam o INSS e são jogados à própria sorte. Além disso, nem sempre contam com o imediato reconhecimento do direito ao benefício por incapacidade:

Sou empregada terceirizada no hospital, estou com mais de cinco anos. Eles não reconheceram a minha doença como acidente de trabalho. Quando vim para cá, foi quando eu fiz a cirurgia, assim fiz perícia e me deram licença [...]. A empresa não fez nenhuma ligação pra saber se ainda estou viva, se melhorei, mas sabem que estou afastada. Eu não tenho mais condições de voltar a trabalhar nessa função. O médico do trabalho já pediu pra me tirar, estou com os papéis aqui, mas não me tiram! Quando eu voltar agora, aí não sei como 
será meu destino. Desde abril que estou de licença. Só sei que já tenho advogada. Na hora que me botarem pra fora eu vou agir, pelos meus direitos, que foi acidente de trabalho [...] (INCERTEZA, grifos nossos).

O empregado tem direito a um ano de estabilidade e o empregador não pode demiti-lo durante esse ano após o retorno, quando reconhecido como doença ou acidente decorrente da atividade laboral.

Em nossas interlocuções, foram recorrentes as narrativas sobre o adoecer, a relação com a vida laborativa e as trajetórias de luta pelo reconhecimento do direito no INSS:

Sinto muitas dores nos braços [...]. Eu engomo no vapor, trabalho há três anos na empresa Y. Dói o pescoço, as costas, meus pés e pernas incham. Saem caroços no punho. Eu fico oito horas em pé. Faço as consultas e exames pagando com abatimento. Não é plano de saúde, é só convênio. A gente paga a metade e a empresa Y paga a outra parte. Tenho bursite, segundo a doutora que bateu a ultrassom. O médico pediu uma tomografia e não tenho condições, é muito caro. A primeira vez que fiz perícia não aceitaram porque eu não tinha nenhum exame. Marcaram o retorno ao trabalho e não voltei, recorri. Hoje, vim para a perícia novamente. O médico acha que essas dores são devidas ao trabalho que realizo, até pediu o meu afastamento dessa profissão, está no atestado. Por enquanto, eu nem estou recebendo pela firma e nem pelo INSS (DORIDIFICULDADE, grifos nossos).

Outros verbalizaram situações de desumanização no atendimento, dificuldade no acesso a consultas e exames no Sistema Único de Saúde (SUS), necessário para o tratamento e apresentação naquele, também questionado, ato pericial do INSS. Apontaram esses elementos aliados a dores e incertezas como agravantes que acompanham e fragilizam ainda mais os momentos de adoecimento, (des)proteção e desemprego:

Ele está com esse problema depois de tanto sofrimento no INSS, que negou várias vezes o seu pedido de aposentadoria especial, tem mais de 25 anos de contribuição. Já andou tanto atrás disso que acabou nessa depressão [...]. Sem resposta ficou numa preocupação de como iria manter a casa, um pai de família [...] Hoje, quem mantém a casa sou eu e minha filha. Estamos agora solicitando um auxílio-doença devido à depressão e perda de audição dele. Nós estamos nessa luta [...] já botamos um processo para ter os direitos dele. A empresa o demitiu doente com perda de audição, pressão alta e sem completar o tempo para aposentadoria. Estamos nessa peleja, ele doente já contratamos um primeiro advogado que nos enganou, mentiu para nós, "comeu” nosso dinheiro. Agora, estamos com outro advogado. [...] ficou o INSS negando, negando, daí a gente teve que partir para a Justiça. Agora, ele está doente, precisa de medicação [...] trabalhou sempre nessa área de metalurgia, como ferramenteiro, sempre de carteira assinada desde 1976 nessa profissão, é uma coisa absurda, chegou o tempo de aposentar e fica nessa humilhação (PELEJA, grifos nossos).

Tenho mais de 20 anos de carteira assinada, nunca achei que iria precisar do INSS. Há três anos fui vítima de um acidente de moto. Um ano após o acidente o INSS me liberou, mas a empresa não me aceita porque o médico do trabalho não me autoriza a laborar, a empresa tem medo que aconteça algo dentro dela e venha a ser responsabilizada. Recorro ao médico do INSS e ele não faz nada, nem lê o atestado e só fala que tenho que ter um documento mais completo. Fiz cirurgia, passei quatro dias em coma, eles falam que eu tenho outra doença. Trabalho com moto, eu posso desmaiar a qualquer momento com cliente ou sem cliente. Tomo vários remédios controlados [...]. Estou de licença (entre aspas) porque o INSS não me paga e nem a empresa quer me pagar. Eu já estou há mais de dois anos sem receber nenhum tostão do INSS, já passei pela reabilitação, já fui, já voltei, parece que os médicos ganham para cortar a gente. Tenho 42 anos, é a primeira vez que estou à procura do INSS nesses 20 anos de carteira assinada, graças a Deus eu tenho meu pai e minha mãe, sou solteiro, todos os meses são quase 300 reais de remédio [...] (DIFICULDADE, grifos nossos).

Esse é meu genro, um rapaz jovem com depressão que trabalha há dez anos à noite num hotel como auxiliar de cozinha. O perito médico disse que poderá fazer uma visita e se ele não estiver em casa poderá ressarcir todos os direitos do INSS. Ele está comigo [...] e estou tensa porque o endereço dele é outro e se o médico for para a casa dele não vai encontrá-lo. [...] Depois o médico vai pensar que estou mentindo [...]. A esposa passa o dia trabalhando como empregada doméstica (HUMILHAÇÃO, grifos nossos).

No conjunto de depoimentos dos trabalhadores desempregados e/ou autônomos, identificamos situação singular, qual seja: já terem tempo de contratos formais com registro em carteira de trabalho, por consequência com vários anos de contribuições destinados a previdência social. Estes interlocutores apresentaram insegurança com a redução de alternativas de proteção social. 
Trabalho como costureira em casa e tenho 11 anos de carteira assinada. Antes, trabalhava na roça, depois, em 1976, vim para Fortaleza com meus filhos. Eu tenho 56 anos de idade. Hoje, eu me sinto doente da coluna e tenho um problema reumático, piorei devido a uma queda que levei, ai fiquei doente. Estou desempregada faz dois anos, doente e nunca dei entrada, estava trabalhando em casa como autônoma. Fui ao médico e ele disse: 'a senhora está doente, não tem condição de trabalhar, vá ao INSS que você tem direito a um benefício'. Eu tenho 56 anos e mulher só se aposenta com 60, ainda faltam quatro anos para chegar a idade de aposentar, se a lei não mudar né? Até poderia trabalhar esses anos, mas eu me sinto impossibilitada (DESPROTEÇÃO, grifos nossos).

Tenho 65 anos, nunca trabalhei com carteira assinada, sempre trabalhei por conta própria. Sou mecânico, no momento, estou desempregado. Estou procurando o '0800', da assistência. Eu nunca trabalhei em empresa grande, trabalhei sempre em oficina pequena (TRABALHOIDESPROTEÇÃO, grifos nossos).

O sujeito identificado como Trabalholdesproteção relacionou a solicitação do benefício assistencial à figura gratuita do " 0800 " pelo fato de não exigir contribuição, diferente do que ocorre com os direitos previdenciários. Indagamos qual era o sentimento de chegar aos 65 anos com a profissão de mecânico e frequentes trabalhos sendo "obrigado" a solicitar o BPC/Loas em vez da aposentadoria e se fazia alguma diferença. Ele respondeu: "demais né, se eu estivesse com carteira assinada ou pagando no INSS, já estava bem resolvido, mas como nunca liguei para isso, quando a gente é novo, a gente não pensa, aí hoje eu estou precisando, e não sai".

Em algumas situações o recorte contributivo da política previdenciária passa a ser de conhecimento desses sujeitos quando buscam o direito e se deparam com a informação. A desinformação parece recorrente e, em geral, lamentam o tempo perdido e reconhecem a importância de contribuir para o INSS, embora alguns socializassem a dificuldade para pagar.

Outros interlocutores, contribuintes sem carteira assinada, buscam o direito previdenciário com a firmeza de acionar um direito conquistado:

Eu estou representando a minha esposa [...] temos uma pequena empresa gráfica [...]. Foi acometida de um câncer de mama no ano passado e está fazendo quimioterapia, começou em fevereiro e em março ela operou, retirou a mama, deu entrada no auxílio doença [...] pagamos o INSS e ela está sem trabalhar, acho que é um direito dela ter acesso a esse benefício (DIREITO CONQUISTADO, grifos nossos).

Outros agradecem por terem um empregador que os orientou, encaminhou e auxiliou na conquista do direito:

Eu era motorista particular, mas perdi minha carteira de motorista há dois anos. Fiquei afastado do trabalho devido ao uso de drogas e álcool. Faço acompanhamento no Caps, estou internado em uma comunidade terapêutica. Já passei por nove internações e essa pessoa que assinava a minha carteira era advogada e quando eu me afastei do trabalho ela deu muita força, ajudou na primeira internação e foi quem correu atrás dessa questão no INSS (GRATIDÃOLEMPREGADOR, grifos nossos).

Em nossas interlocuções, os sujeitos de direitos demonstraram que vem de trajetórias envolvendo trabalho precário, desemprego, perda de vínculos sociais e adoecimentos. Alguns têm dificuldades de reconhecimento e indícios evidentes de que foram ocasionados pela atividade laboral. Submetidos a percalços para realizarem exames e tratamentos de saúde, com tentativas no SUS, mas acabam pagando exames em clínicas populares. No âmbito da previdência, enfrentam condicionalidades para o reconhecimento do direito. Alguns desses sujeitos perderam o vínculo previdenciário e, após anos de trabalho, buscam como alternativa o reconhecimento do BPC/Loas.

No geral, demonstraram o percurso nas políticas de seguridade social e trabalho com trajetórias tortuosas que ensejam desgastes físico e emocional, traduzidos em relatos de sofrimentos, incertezas e de dores. Encontramos, também, narrativas que expressaram satisfação e alívio pela obtenção do reconhecimento imediato do direito previdenciário, pela atenção e auxílio do empregador, além da intervenção e acompanhamento da rede de proteção social voltadas para esse fim.

No trabalho, chamaram-nos atenção os vínculos precarizados, terceirizados com ambientes de trabalho insalubres e adoecedores, além de empregadores que demitem ao perceberem os sinais e sintomas de adoecimento do corpo e/ou mente dos trabalhadores expostos a tais condições laborais. 
Após o desgaste da saúde, os sujeitos sociais, expostos a jornadas e rotinas extenuantes, aos agravos e riscos ambientais, buscam a rede privada ou pública do SUS para consultas, exames e cirurgias. Enfrentam longas esperas e/ou dificuldades de acesso. Relatam que os vínculos de amizades com quem trabalha nessa área, às vezes, facilita o acesso.

Por fim, chegam à previdência social em busca de substituição da renda que auferiam no trabalho por meio do requerimento do auxílio doença previdenciário ou acidentário, mas nem sempre encontram o reconhecimento de imediato. Há muita reclamação dos sujeitos, quanto ao poder soberano do perito médico, ao se submeterem ao exame pericial para a constatação da incapacidade laborativa. Relataram a palavra humilhação e o desgaste emocional que ocasionam a piora no adoecer em razão do modo como são recepcionados e de como suas informações são postas em dúvida. Em algumas interlocuções foi mencionada a busca do poder judiciário para obter o reconhecimento do direito previdenciário. As observações, aliadas às narrativas dos sujeitos durante a pesquisa de campo, levaram-nos a um olhar mais atencioso ao fenômeno da judicialização na previdência social. Trata-se de um atalho frequentemente adotado na trajetória do sujeito, geralmente, alongando o percurso no processo de reconhecimento ou não do direito requerido.

\section{Considerações}

As narrativas dos interlocutores promovem a reflexão sobre as relações e os limites entre o adoecimento dos sujeitos, o mundo do trabalho e as conquistas dos direitos sociais e políticos, produtos históricos das lutas e reinvindicações dos trabalhadores. Muito dos avanços expressos na legislação social, consagrados nos direitos sociais, envolvem a seguridade e seu tripé, com destaque à saúde do trabalhador. Os instrumentos jurídicolegais parecem ser facilmente violados e quase não dão conta da precariedade do trabalho no contexto da mundialização do capital. Um agravante nesse contexto são as evidências da pouca concretização do diálogo intersetorial, no mínimo, entre previdência, trabalho e saúde, o que dificulta a intervenção para conter os riscos e agravos à saúde do trabalhador. Este é um dos elementos que estanca a promoção do trabalho decente, protegido e seguro nas cenas vividas pelos sujeitos de direitos.

Os instrumentos jurídico-institucionais ${ }^{8}$ de proteção social à saúde e segurança do trabalhador possuem significativa importância, pois exercem controle sobre as leis vorazes do mercado. Nas narrativas dos sujeitos de direitos, entretanto, há relatos de trajetórias sinuosas com pouca eficácia desses mecanismos na realidade cotidiana desses trabalhadores. Em situação de extrema precarização estão os desempregados, autônomos/ informais, pois, enfraquecidos no seu poder de organização, nem sequer dispõem da possibilidade de acionar tais mecanismos para a proteção que a eles não se destinam. Há uma crescente desumanização do trabalho no contex to do capitalismo fetichizado e financeirizado, intensificando a relação entre trabalho e adoecimento, o que fragiliza os sujeitos de direitos, dada a maior insegurança no mundo do trabalho em suas múltiplas dimensões e complexidades.

As narrativas dos interlocutores confirmam outras investigações, sobretudo de Vianna (2005), Marques e Mendes (2005), Boschetti (2006) e Ipea (2009), os quais apontam alguns paradoxos entre a estrutura formal de proteção social expresso na Constituição Federal de 1988 (CF/1988), com uso da terminologia seguridade social, e a realidade cotidiana dos sujeitos de direito. Ainda assim, a linguagem do direito exerce uma atribuição prática e política, pois com ela se atribui uma força particular às reivindicações individuais e coletivas e lança luzes sobre a histórica desigualdade social. Nesse percurso, a diferença entre o direito reivindicado e o direito reconhecido e protegido fica um pouco menos oculto.

Pelo exposto, a seguridade social, por conseguinte, a previdência e os seus desafios para torná-la um sistema de proteção social universal e equânime, com amplo conjunto de direitos, envolvem uma série de outras estratégias articuladas, como: fortalecer o espaço de socialização da política e de luta dos trabalhadores; orçamento público com controle social e política tributária justa e democrática, que priorize a progressão dos impostos e redistribuição da renda e da riqueza; ampliação do conceito de seguridade social e superação da lógica do seguro; política ampla de emprego e mecanismos de acesso aos desempregados e políticas de redistribuição da riqueza com capacidade para reduzir desigualdades e não somente combate à pobreza.

\section{Referências}

ALVES, G. Dimensões da reestruturação produtiva: ensaios de sociologia do trabalho. Londrina: Práxis; Bauru: Canal 6, 2007. ANTUNES, R. (Org.). Riqueza e miséria do trabalho no Brasil. São Paulo: Boitempo, 2006. 
. Os sentidos do trabalho: ensaio sobre a afirmação e a negação do trabalho. São Paulo: Boitempo, 2001.

BOSCHETTI, I. Seguridade social e trabalho: paradoxos na construção das políticas de previdência e assistência social no Brasil. Brasília: Letras Livres, UnB, 2006.

BRASIL. Constituição da República Federativa do Brasil. Brasília: Senado Federal: Centro Gráfico, 1988.

CANCLINI, N. G. Consumidores e cidadãos: conflitos multiculturais da globalização. Tradução de Maurício Santana Dias. Rio de Janeiro: Editora UFRJ, 2008.

CHESNAIS, F. A mundialização do capital. Trad. Silvana Finzi Foá. São Paulo: Xamã, 1996.

DERRIDA, J. Força de lei: o fundamento místico da autoridade. Tradução de Leyla Perrone Moisés. São Paulo: WMF Martins Fontes, 2007. . Anne Dufourmantelle convida Jacques Derrida a falar da hospitalidade. Trad. Antônio Romane. São Paulo: Escuta, 2003.

FLICK, U. Desenho da pesquisa qualitativa. Trad. Roberto Cataldo Costa. Porto Alegre: Artmed, 2009.

INSTITUTO DE PESQUISA ECONÔMICA APLICADA. Muitos avanços, mas ainda é pouco: 20 anos de políticas sociais. [S.1.], set./out. 2009. Disponível em: 〈http://www.ipea.gov.br>.

JERUSALÉM: via-crúcis. Guia do estudante online. 01, abr. 2004. Disponível em: <http://guiadoestudante.abril.com.br/aventurashistoria/jerusalem-via-crucis-433613.shtml>. Acesso em: 23 de janeiro de 2015.

MARQUES, R. M; MENDES, A. Desvendando o social no governo Lula: a construção de uma nova base de apoio. In: PAULA, João de Antonio (Org.). Adeus ao desenvolvimento: a opção do governo Lula. Belo Horizonte: Autêntica, 2005.

MÉSZÁROS, I. A Crise Estrutural do Capital. Trad. Francisco R. Cornejo. Rio de Janeiro: Boitempo, 2009.

TELLES, V. S. Direitos Sociais: afinal do que se trata? Belo Horizonte: Ed. UFMG, 1999.

VIANNA, M. L. T. W. Seguridade social e combate a pobreza no Brasil: o papel dos benefícios não contributivos. In: Proteção social: dilemas e desafios. São Paulo: Hucitec, 2005.

ZINET, C. Terceirização avança sobre direitos trabalhistas. Revista Caros amigos. Ano XV, nº 179, 2012.

\title{
Notas
}

1 É uma expressão do modo como o Estado brasileiro enfrentou a crise de múltiplas dimensões que atingiu a sociedade brasileira, sobretudo a partir dos anos de 1980. A visibilidade maior foi dada aos aspectos econômicos manifestados por altos índices de inflação, endividamento externo, recessão e desemprego, o que obscureceu os componentes políticos e institucionais, cuja principal expressão é a crise do Estado. Desequilíbrio fiscal, desordem das contas públicas instabilidade monetária, seriam identificados como fatores propulsores do indispensável ajuste estrutural.

2 SEVERIANO, E. M. O. Previdência social e dilemas da seguridade no Brasil contemporâneo: trajetórias de "sujeitos de direitos" entre o trabalho e o adoecimento. Tese (doutorado), Universidade Federal do Ceará, Fortaleza, 2012.

3 Para atender à garantia do sigilo dos interlocutores, utilizamos para a apresentação de trechos dos depoimentos palavras-chave que os mesmos atribuem às suas vivências na busca pelo reconhecimento do direito ao benefício por incapacidade. Assim, a investigação respeitou as normas éticas que regem a pesquisa científica com seres humanos, conforme Resolução 466/2012 do Conselho Nacional de Saúde (CNS), solicitando-se o consentimento livre e esclarecido dos entrevistados, bem como a autorização para realizar as observações e a preservação do anonimato dos informantes. O projeto foi aprovado pelo Comitê de Ética em Pesquisa da Universidade Federal do Ceará.

4 Exemplificamos alguns segmentos articulados de categorias profissionais e setores de grupos organizados, como as cooperativas de trabalho, economia solidária, artesãos, fóruns de lutas de mulheres, entre outras categorias profissionais.

5 Esse grupo faz parte de uma das atividades desenvolvidas pela Secretaria de Saúde do Sindicato dos Bancários. Reúne-se bimestralmente como objetivo de apoiar os bancários portadores de qualquer tipo de problemas e doenças ocupacionais, visando criar um intercâmbio de informações e apoio entre os mesmos.

6 Disponível em: http://guiadoestudante.abril.com.br/aventuras-historia/jerusalem-via-crucis-433613.shtml. Acesso: 23 jan. 2015.

7 Tomando a liberdade de nos apropriarmos da reflexão de Derrida (2007), a previdência, com o seu princípio de universalidade de atendimento, parece ser para todos, mas há uma série de condicionalidades de acesso aos direitos por ela administrados. Geralmente a força da lei se sobrepõe à condição humana, o sentido humano é suspenso para imperar a força da lei.

8 Rede Nacional de Atenção Integral à Saúde do Trabalhador (Renast) e Centro de Referência em Saúde do Trabalhador (Cerest).

\section{Evânia Maria Oliveira Severiano}

evaniaseveriano@gmail.com

Doutora em Sociologia pela Universidade Federal do Ceará (UFC)

Docente na Faculdade Metropolitana da Grande Fortaleza (Fametro)

Assistente Social do Instituto Nacional do Seguro Social

\author{
Alano do Carmo Macêdo \\ alanomacedo@yahoo.com.br
}


Doutorando em Serviço Social pela Universidade Federal de Santa Catarina (UFSC) Assistente Social do Instituto Nacional do Seguro Social

\section{Gerência Executiva do INSS}

Rua Pedro Pereira, 383, Centro

Fortaleza - Ceará - Brasil

CEP: 60035-000 